\title{
Return to Public Health- Undeliverable letters of Communicable Disease Patients
}

\author{
Uzay Kirbiyik*1, 2, Hassan Shah, 2, Patrick T. Lai' ${ }^{4,2}$, Jennifer L. Williams², Brian E. Dixon ${ }^{1,2}$ \\ and Shaun Grannis ${ }^{3,2}$
}

${ }^{1}$ IU Richard M. Fairbanks School of Public Health, Indianapolis, IN, USA; ${ }^{2}$ Regenstrief Institute, Indianapolis, IN, USA; ${ }^{3}$ ndiana

University, School of Medicine, Indianapolis, IN, USA; ${ }^{4}$ School of Informatics and Computing, Indianapolis, IN, USA

\section{Objective}

Explore causes of undelivered letters sent by public health departments to patients with communicable diseases.

\section{Introduction}

Preventing communicable disease spread is a primary objective for public health $(\mathrm{PH})$. Reaching contagious people in a timely manner is essential to limit disease spread. Notifying patients of their infectious status also serves as an official reminder of social and legal responsibilities. The Marion County Public Health Department (MCPHD) sends disease information and Notice of Privacy Practices to patients using the United States Postal Service (USPS). We examined communicable disease cases with undelivered mail to ascertain failure causes and rates.

\section{Methods}

We reviewed completed case files for 3 communicable diseases investigated by MCPHD. MCPHD sends a letter to each of these new positive cases. The addresses are gathered from provider and lab reports and from other sources. When the letters are undeliverable, PH staff logs these mails to the case files. We reviewed all cases with undelivered letters and identified source of address, reason for return, and patient demographics.

\section{Results}

The letter return rates among diseases were significantly different $\left(X^{2} p=0.0006\right)$. The age distributions among races were also significantly different ( $t$-test $p=0.002)$; mean age for Caucasian and African American were 36 vs. 49 years respectively. The proportions of USPS endorsements for the undelivered mail were as follows:

Attempted- not known 36\%

Not deliverable as addressed $22 \%$

No such number $16 \%$

Moved left no address $10 \%$

Insufficient Address 9\%

Forward time expired 2\%

No Mail Receptacle 1\%

Refused $1 \%$

Vacant $1 \%$

Analysis of root causes for undeliverable addresses yielded a framework of address information flow (fig. 1). Since the communication between the patient and the provider is not documented, it is not possible to accurately discern the source of the initial error.

\section{Conclusions}

Several factors contributed to undeliverable mail. MCHD staff suggests some of these are due to patients giving false information to avoid health bills. We have come across a significant number of institutions (15\%), like churches and shelters for homeless, used for address. We also noted many drug abuse and incarceration reports among the undeliverable cases. This is expected due to socio-economic problems and communicable diseases being common with these groups. The differences among racial groups also suggest other cultural factors in play and need further exploration.

$\mathrm{PH}$ staff resends the notification if they can figure out the reason for the returned mail (e.g. typos, choose different address, check the address with the provider/patient). While this is another burden for PH, the actual delivery rates are likely higher than what initially reported.

However, letters may not always be delivered to the person intended. An earlier study found $13.3 \%$ of letter sent to fictitious people did not return, but all invalid addresses did [1]. Further, we were able to geo-locate $31 \%$ of undeliverable addresses labelled as "No such number" by USPS which we classified as postal error (5\%).

Due to its fragmented nature, there is no one solution to undeliverable mail problem. Technical solutions may include incorporating USPS address verification system, sending an initial confirmatory mail by the provider or using phone or email as alternative. Our framework allows us to establish a baseline for future research including cost-effectiveness analyses for streaming lining the process for process improvements.

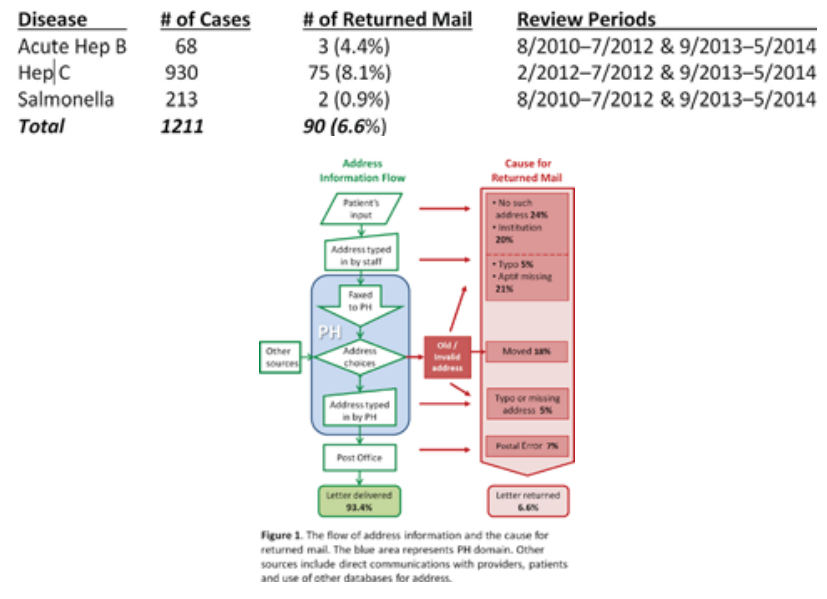

Keywords

Return to Sender; Undeliverable mail; Communicable disease notification; Patient address

\section{Acknowledgments}

We thank the staff at MCPHD for their help with this research.

\section{References}

1. Sandler RS, Holland KL. Fate of incorrectly addressed mailed questionnaires. J Clin Epidemiol. 1990;43:45-7.

\footnotetext{
*Uzay Kirbiyik

E-mail: ukirbiyi@iupui.edu
} 